\title{
Frédéric Fladenmuller, Télescopie. La science du genre d'«A la recherche du temps perdu»
}

\section{Emanuele Kanceff}

\section{(2) OpenEdition}

1 Journals

\section{Edizione digitale}

URL: http://journals.openedition.org/studifrancesi/35123

DOI: 10.4000/studifrancesi.35123

ISSN: 2421-5856

\section{Editore}

Rosenberg \& Sellier

\section{Edizione cartacea}

Data di pubblicazione: 1 novembre 2005

Paginazione: 447

ISSN: 0039-2944

\section{Notizia bibliografica digitale}

Emanuele Kanceff, «Frédéric Fladenmuller, Télescopie. La science du genre d’«A la recherche du temps perdu»», Studi Francesi [Online], 146 (XLIX | II) | 2005, online dal 30 novembre 2015, consultato il 18 avril 2021. URL: http://journals.openedition.org/studifrancesi/35123; DOI: https://doi.org/10.4000/

studifrancesi.35123

Questo documento è stato generato automaticamente il 18 avril 2021.

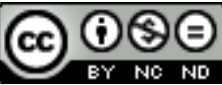

Studi Francesi è distribuita con Licenza Creative Commons Attribuzione - Non commerciale - Non opere derivate 4.0 Internazionale. 
Frédéric Fladenmuller, Télescopie. $L a$ science du genre d' "A la recherche $d u$ temps perdu»

Emanuele Kanceff 


\section{NOTIZIA}

FRÉDÉRIC FLADENMULLER, Télescopie. La science du genre d'«A la recherche du temps perdu», New York, Peter Lang Publishing («Currents in Comparative Romance Languages and Literatures», 106), 2002, pp. 126.

1 L'autore si propone di studiare il ruolo della scienza in Proust, elemento chiarificante del romanzo senza essere per tanto riduzione a funzione analitica. Strumento per eccellenza dell'investigazione dell'inconscio, la scienza è oggetto di una inversione filosofica e lessicale. Dalla visione telescopica del narratore, che costituisce il primo strumento analitico dello spazio interiore, all'osservazione meticolosa dei personaggi del romanzo, Proust si serve della scienza per evocare le leggi che presiedono al cosiddetto «tempo incorporporato», poiché l'arte vive come la carne; dunque utilizza la scienza a fini utilitari, come strumento per creare la verosimiglianza del racconto realistico, senza per questo abbandonare le matrici idealistiche del suo romanzo: grazie alla scienza «l'approche téléscopique du narrateur, - dice Fladenmuller, - c'est le fonds qui prend forme et devient réel aux yeux du lecteur».

2 Sicché, Proust utilizza tutte le risorse della scienza, nel senso più largo del termine, e fa ricorso, per legittimare la sua visione, sia alle leggi fondamentali della natura che reggono l'universo vegetale e animale, sia allo studio approfondito dei fenomeni naturali. Si può dire dunque che trasformi la sua ricerca in una vera e propria ricerca scientifica, in cui manipola una pluralità d'elementi a carattere scientifico che l'autore designa con il termine di téléscopie. 